Documentación de las Ciencias de la Información ISSN-e: $1988-2890$

https://dx.doi.org/10.5209/dcin.78680

\title{
Instagram, la nueva apuesta por el contenido audiovisual de la prensa española
}

Antonio Díaz-Lucenaํㅡ, Victoria Mora De La Torre ${ }^{2}$

Recibido: 5 de noviembre de 2021 / Aceptado: 29 de noviembre de 202

Resumen. Esta investigación analiza la presencia de la prensa española en Instagram. Una plataforma eminentemente visual donde los diarios nacionales han empezado a posicionarse, más tarde que el resto de sus homólogos internacionales. No obstante, estos últimos años, el crecimiento de la prensa española en Instagram está siendo muy significativo. Además, se ha advertido que su inversión en contenidos audiovisuales empieza a marcar la diferencia con el resto de países occidentales. Se abordará este estudio mediante un enfoque cuantitativo con el uso de análisis descriptivos e inferenciales de los datos recogidos de sus cuentas de Instagram durante doces meses de las siguientes rotativas nacionales (El País, La Vanguardia, El Mundo, ABC, 20 Minutos, El Español, elDiario.es y El Huffpost) e internacionales (Le Monde, Le Parisien, Le Figaro, Bild, FAZ, Corriere della Sera, La Repubblica, The Guardian, The Times, The New York Times y The Washington Post).

Palabras clave: Instagram, Redes sociales; Prensa digital; Medios; Empresas periodísticas

\section{[en] Instagram, the Spanish press' new commitment to audiovisual content.}

\begin{abstract}
This research analyses the presence of the Spanish press on Instagram. An eminently visual platform where national newspapers have begun to position themselves later than the rest of their international counterparts. However, in recent years, the growth of the Spanish press on Instagram has been very significant, but it has also been announced that its investment in audiovisual content is beginning to make a difference versus the rest of Western countries. This study will be conducted through a quantitative approach with the use of descriptive and inferential analyzes of the data collected from their Instagram accounts during twelve months of the following national newspapers (El Pais, La Vanguardia, El Mundo, ABC, 20 Minutos, El Español, elDiario.es and El Huffpost) and international press (Le Monde, Le Parisien, Le Figaro, Bild, FAZ, Corriere della Sera, La Repubblica, The Guardian, The Times, The New York Times and The Washington Post).
\end{abstract}

Keywords: Instagram; Social networks; National press.

Sumario. 1. Introducción 2. Estado de la cuestión 3. Metodología y objetivos 4. Análisis. 5. Discusión 6. Conclusiones 7. Bibliografía

Cómo citar: Díaz-Lucena, A., Mora de la Torre, V. (2022) Instagram, la nueva apuesta por el contenido audiovisual de la prensa española, en Documentación de las Ciencias de la Información. 45 (1), 71-81.

\section{Introducción}

Las Redes Sociales, en adelante RRSS, se han constituido como uno de los principales pilares de la comunicación en Internet. Sus usuarios han aumentado significativamente en los últimos años. Un $13 \%$ de crecimiento interanual o, dicho de otra manera, 1,3 millones cada segundo durante el año 2020.

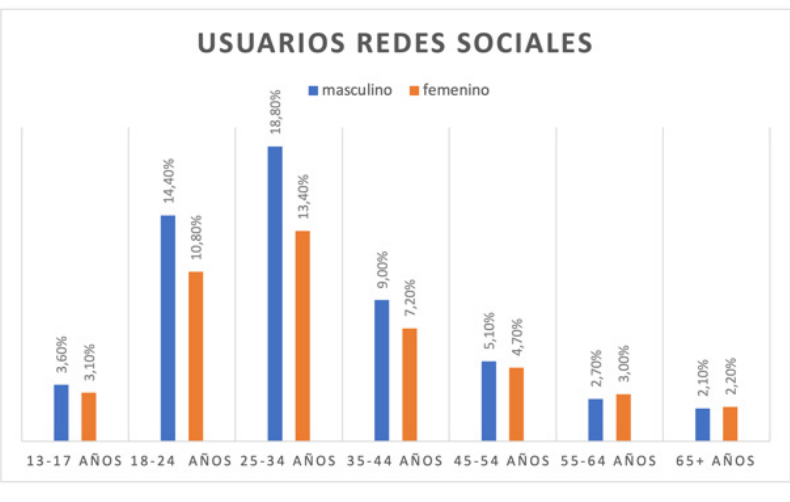

Gráfico 1 Usuarios de las Redes Sociales por edad y género. Fuente: Informe Digital 2021 de We Are Social

\footnotetext{
Universidad Rey Juan Carlos (Madrid)

E-mail: Antonio.diaz@urjc.es

ORCID: https://orcid.org/0000-0002-4234-0850

2 Universidad Rey Juan Carlos (Madrid).

E-mail: victoria.mora@urjc.es

ORCID: https://orcid.org/0000-0002-5221-6538
} 
De los 31,7 millones de usuarios de Internet (Estudio anual de redes sociales, 2021) que tenemos en España, la franja de 16 a 65 años supone el 87\% de los internautas que emplean la RRSS a nivel nacional. Si se mira al tipo de audiencia por edad y género se puede advertir en el gráfico 1, cómo los principales grupos se ubican en la franja de 18 a 24, 25 a 34 y 35 a 44 años. En cuanto a la variable de género, los hombres se posicionan en primer lugar. Y en el cómputo general, el empleo de redes sociales crece notablemente en todas las generaciones.

Asimismo, las plataformas con más demanda son: Facebook (75\%), seguido de Instagram (64\%) y Twitter (51\%). Su progresión y desarrollo se ha percibido y entendido como una oportunidad de expansión de los medios de comunicación, los cuales han sabido aprovechar y adaptarse a cada una de las plataformas existentes para buscar la interacción del ciudadano con sus contenidos (Herrero, 2012). Una de las principales variables que ha motivado esta subida reside en el incremento del uso de dispositivos móviles inteligentes en casi un 94,5\%, frente a otros modos de acceso como las Smart $T V$, portátiles, tabletas u otros (AIMC, 2021). Una subida impulsada por la implementación de novedades tecnológicas, cuya democratización ha sido clave a la hora de instaurar nuevas rutinas sociales en la red. Así pues, desde 2019 más de la mitad del tráfico en internet se realiza desde el dispositivo móvil. El tiempo medio que un individuo pasa conectado a la red a través del móvil en 2019 ha sido superior a 2018 (informe Ditrendia 2020). Esta inclinación augura un crecimiento sistemático que será favorecido por el uso que se da al terminal y las mejoras en las transferencias de datos. Con todo, los datos que se extraen pronostican un futuro realmente atractivo para estas plataformas (Shearer, 2021).

Instagram, originariamente Burb, fue creada por Kevin Systrom y Mike Krieger en California en 2010. Tras dos años de su puesta en marcha fue adquirida repentinamente por Facebook. Este hecho supuso un gran empuje hacia la adquisición de nuevos usuarios, crecimiento económico y sinergias entre aplicaciones. De esta forma, Facebook e Instagram se interconectaron de manera que una publicación que se hace en una de ellas se difunde de forma instantánea en la otra y viceversa, siempre que el usuario lo configure en la aplicación. Una posibilidad que desde luego aporta agilidad y rapidez en la comunicación.

Se puede afirmar que Instagram ha revolucionado el mundo de la fotografía y del vídeo en las RRSS. $\mathrm{Su}$ éxito en gran parte se debe a las opciones de personalización de la experiencia en función de sus propios intereses con el empleo de un feed. Esta técnica consigue catalogar las publicaciones de acuerdo con el uso específico de cada usuario. De esta manera, esta red favorece la comunicación y la conexión entre los contactos mediante contenido en vídeo de un máximo de treinta segundos y de fotografías que conforman los reels en las historias en abierto o privado.

Como todas las aplicaciones de este tipo, poco a poco, han ido incorporando actualizaciones sustanciales para mejorar su funcionamiento como ha sido, por ejemplo, la inclusión del Hashtag en 2011. Esta técnica permite asociar una publicación a un contenido específico, etiquetar a personas determinadas que aparecen en una fotografía o incluso enlazar con un sistema de mensajería instantánea entre dos contactos o seguidores.

En 2015-2016 se produce un salto cualitativo en sus operaciones con la implementación de anuncios en las stories. De la misma forma, en 2018 se agrega la posibilidad del vídeo en streaming gracias a la incorporación de Instagram Tv (IGTV) que intenta competir con Youtube. Esta novedad facilita y simplifica la retransmisión en tiempo real de eventos con una duración de diez minutos. Archivos, que una vez finalizados, se quedan guardados como elementos audiovisuales, que pueden oscilar entre tres segundos a una hora dependiendo del tipo de producto del que se trate. Por ejemplo, los feed alcanzan una extensión máxima de un minuto, las historias llegan a los quince segundos, -una opción que permite enlazar varias- y, los directos se extienden hasta una hora. Una limitación temporal que también está presente en IGTV; canal similar a Youtube.

La evolución de las RRSS y de forma específica de Instagram no ha pasado desapercibida para las empresas mediáticas, como ya se ha avanzado. El periodismo está cambiando y las redacciones de los medios se han remodelado hacia una estructura mucho más interactiva. Estas herramientas han adquirido diferentes funciones en el ámbito de la información y de la comunicación, pues están sirviendo como fuentes periodísticas (Herrera et al., 2012; Benaissa, 2018), para generar engagement con sus seguidores (Góngora et al., 2020), así como el uso del contenido audiovisual que proporcionan y que complementa a determinadas noticias (Longhi-Heredia et al., 2021), pero también su empleo en la distribución de información (Pérez-Soler, 2017). Todo ello toma forma y sentido con la irrupción de la actividad periodista denominada MOJO o Mobile Journalism (Burum et al., 2015; Canavilhas et al., 2016) que consiste en realizar periodismo de movilidad haciendo uso de la inmediatez, facilidad de acceso y la geolocalización presente en los dispositivos. Factores que agregan mayor personalización de los contenidos en función de los intereses y de los gustos del propio usuario generando mayor empatía y complicidad (Hedley, 2012). Aspecto que ha provocado cambios estructurales importantes en los medios de comunicación debido a la unificación de procesos de producción, distribución y consumo mediante una misma plataforma (Santín et al., 2020; Kalogeropoulos et al., 2017; García-Avilés, 2015). 


\section{Objetivos e hipótesis}

El objetivo central de este trabajo es el estudio del uso que la prensa española hace de Instagram durante un periodo de doce meses, que comprenden los meses de junio de 2020 a julio de 2021. De éste derivan otros más específicos: 1) conocer el progreso y los esfuerzos de la prensa española en esta plataforma; 2) comparar el trabajo de la prensa española con sus homólogos internacionales; y 3 ) comprobar la penetración e interacciones que causa en la audiencia el contenido publicado.

De todo ello, surgen dos hipótesis de trabajo que se intentarán contestar a lo largo del análisis propuesto:

- H.1. La prensa española ha incrementado su presencia en estos doces meses en Instagram, y estos esfuerzos están llevando a los diarios españoles a crecer más que sus homólogos internacionales.

- H.2. La prensa española está empezando a sobresalir en la producción y publicación de contenido audiovisual en Instagram.

\section{Metodología}

Abordaremos esta investigación desde un enfoque cuantitativo con un análisis de datos clásico basado en procesos secuenciales y probatorios como el efectuado por Mayoral et al. (2016). Así pues, se estructurará de la siguiente manera:

1. Observación previa de las cuentas de los medios seleccionados en Instagram;

2. Recogida de los datos que se consideran necesarios para este análisis:

a) fecha de apertura de la cuenta;

b) número de seguidores;

c) número de publicaciones totales en la cuenta y mensuales en el periodo seleccionado;

d) número de interacciones con el contenido publicado en el periodo seleccionado;

e) número de seguidores adquiridos durante el periodo seleccionado.

3. análisis de los datos extraídos para demostrar las siguientes variables:

a) crecimiento o descenso del número de emisiones y de interacciones logradas en el periodo establecido respecto a años anteriores;

b) comparación de los resultados entre medios de prensa nacionales e internacionales.

4. Discusión y conclusiones sobre los resultados obtenidos.
El marco temporal elegido para este estudio comprende doce meses (julio 2020 a junio 2021). De este modo, se ha procedido a extraer estos datos mediante el uso del software del reputado proveedor Keyhole de las cuentas de Instagram de cuatro diarios tradicionales (El País, La Vanguardia, ABC y El Mundo) y cuatro diarios nativos digitales (20 Minutos, El Español, elDiario.es y El Huffpost). Su selección se ha llevado a cabo con apoyo en cuatro variables:

1. diarios generalistas,

2. más leídos en el país,

3. número de seguidores,

4. visibilidad en Instagram.

Si bien nuestro objeto de estudio se centra en la prensa española citada, para lograr los objetivos mencionados se requiere también del análisis de una muestra de la prensa internacional. Con este fin, se han seleccionado periódicos de seis países de Occidente con base a:

1. ranking de diarios más leídos y venta de ejemplares en su país de origen en el caso de la prensa no nativa digital,

2. número de seguidores,

3. visitas y visibilidad en Instagram.

Selección de prensa internacional: Le Monde, Le Parisien, Figaro Live, Bild, FAZ, Corriere della Sera, La Repubblica, The Guardian, The Guardian News, The Times \& Sunday Times, The Washington Post, The New York Times.

\section{Resultados del análisis}

\subsection{Seguidores, creación de la cuenta y número de publicaciones}

En la tabla 1 se muestran las siguientes variables seleccionadas: el nombre de la cuenta, el total de seguidores, la fecha de apertura de esta, el número de publicaciones totales y la cifra de los mensajes generados en estos doce meses por las ocho cabeceras escogidas. Algunos de los datos expuestos llaman poderosamente la atención, como han sido: 1) la diferencia de seguidores de El País con el resto de diarios; 2) la fecha de apertura de las cuentas en Instagram que podría establecerse para todos entre 2014 y 2015 (se verá que algo más tarde que en otros países internacionales); y 3 ) el número total de mensajes emitidos por El Mundo. 


\begin{tabular}{|l|c|c|c|c|c|}
\multicolumn{1}{c}{ Instagram } & \multicolumn{1}{c}{ Cuenta } & \multicolumn{1}{c|}{ Seguidores } & Fecha & Posts Totales & Posts 365 \\
\hline El País & el_pais & 1.201 .632 & 4-sept-13 & 7.018 & 1.731 \\
\hline El Mundo & elmundo_es & 553.815 & 23 -oct-15 & 10.354 & 2.261 \\
\hline ABC & abc_diario & 381.999 & 2 -dic-14 & 7.459 & 2.587 \\
\hline La Vanguardia & lavanguardia & 558.788 & 8 -dic-15 & 8.988 & 3.014 \\
\hline El Español & elespanol2015 & 95.445 & 1-ene-15 & 4.302 & 1.430 \\
\hline elDiario.es & eldiarioes & 162.209 & 3-ene-17 & 2.202 & 984 \\
\hline El HuffPost & elhuffpost & 266.630 & 14-feb-13 & 3.357 & 1.284 \\
\hline 20 Minutos & $20 \mathrm{~m}$ & 204.584 & 20-may-12 & 4.165 & 1.614 \\
\hline
\end{tabular}

Tabla 1 Información cuentas de los periódicos españoles seleccionados. Fuente: Elaboración propia.

Si se analiza el porcentaje de crecimiento a través de los impactos publicados en estos doce meses con respecto al total de mensajes en Instagram se observa que las cifras son verdaderamente significativas.

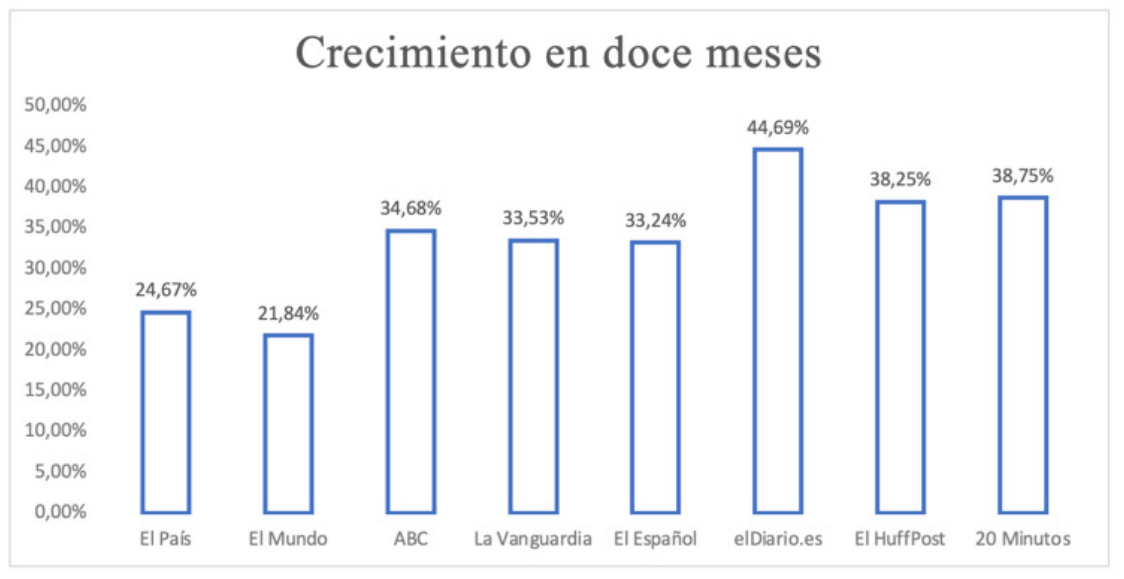

Gráfico 2 Número de mensajes de las diferentes cuentas en Instagram. Fuente de elaboración propia.

Así pues, la tendencia general se muestra ascendente especialmente en los diarios nativos digitales y en $A B C$. Liderando este bloque se posiciona elDiario. es que crece casi un $50 \%$ en doce meses. Si bien $E l$ Mundo, La Vanguardia y El País mantienen una pauta alcista, son medios que irrumpieron en esta red social antes que el resto donde adquirieron una consolidada cifra de seguidores, que en la actualidad les facilita la penetración de sus mensajes y la obtención de interacciones de la audiencia con sus contenidos, aunque con matices, como se expondrá a continuación.

La actividad de los diarios en Instagram, en comparación con plataformas como Twitter o Facebook, donde se llegan a publicar decenas de mensajes diarios, sigue siendo muy inferior. La media de impactos de la prensa española en esta red es de 4 a 5 mensajes diarios como se puede apreciar en el gráfico 3. Se debe anotar que el bloque de prensa tradicional se encuentra en medias superiores, entre 5 y 6 mensajes por día. Sin embargo, los nativos digitales se mueven en una pauta de 3 a 4 publicaciones. Es un dato para tomar en consideración, pues con menos impactos muchos de ellos alcanzan más retorno en interacciones. Aspecto que se abordará con más detenimiento en el siguiente apartado.

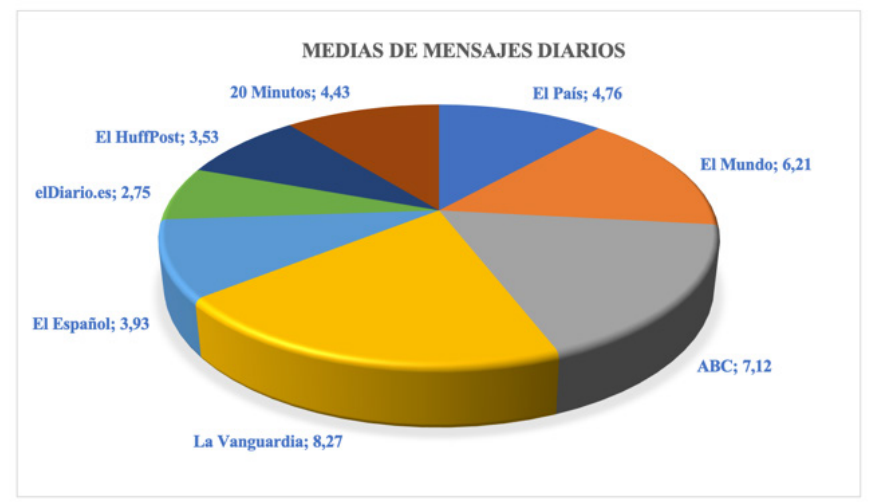


Con todo, la tendencia de la prensa española en Instagram mantiene una pauta de progresión que confirma el gasto y el desarrollo que estos diarios están acometiendo, pero algunas dudas surgen a nuestro paso. Es por ello que su estudio agregará más información sobre el tamaño de la inversión, la importancia del momento en que se está ejecutando o los elementos constitutivos del propio mensaje. Con este fin se compararán los datos expuestos previamente con los extraídos de otros periódicos internacionales que se exponen en la tabla 2.

\begin{tabular}{|l|l|c|c|c|c|}
\hline \multicolumn{1}{c}{ Instagram } & \multicolumn{1}{c}{ Cuenta } & Followers2 & \multicolumn{1}{c|}{ Fecha } & Posts Totales & Posts 365 \\
\hline Le Monde & lemondefr & 1.487 .988 & 26.-abril-12 & 8.665 & 1.284 \\
\hline Le Parisien & leparisien & 426.541 & 15-dic.-14 & 2.617 & 382 \\
\hline Le Figaro & lefigarofr & 527.838 & 3-jun.-13 & 6.078 & 1.241 \\
\hline Bild & bild & 657.035 & 23-ago.-11 & 12.722 & 1.891 \\
\hline FAZ & faz & 480.681 & 13-abr.-12 & 13.200 & 4.228 \\
\hline Corriere della Sera & corriere & 1.106 .489 & 26-jul.-13 & 18.340 & 6.880 \\
\hline La Repubblica & larepubblica & 1.514 .510 & 8-nov.-12 & 13.523 & 2.415 \\
\hline The Guardian & guardian & 4.533 .410 & 10-may.-12 & 6.841 & 964 \\
\hline The Times & thetimes & 827.752 & 23-ene.-14 & 6.462 & 925 \\
\hline The New York Timm & nytimes & 13.423 .563 & 29-dic.-14 & 10.848 & 1.757 \\
\hline Washington Post & washingtonpost & 4.895 .380 & 24-mar.-11 & 9.316 & 2.129 \\
\hline
\end{tabular}

Tabla 2. Información cuentas de los medios internacionales seleccionados. Fuente: Elaboración propia

Destaca en primera instancia la temprana apertura de sus cuentas. Si en el caso español la media rondaba 2014 como fecha de inicio, los medios internaciones se sitúan dos años antes, entre 2012 y 2013. Asimismo, el número de seguidores que mantienen estas rotativas es realmente llamativo, aunque no tanto la actividad que han registrado en los últimos doce meses en relación con el total de

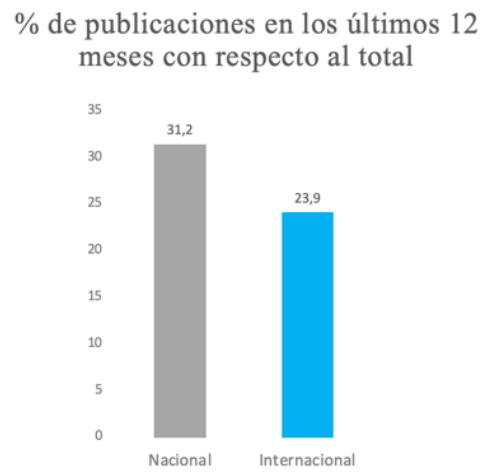

Gráfico 4 Porcentaje de las publicaciones realizadas por los medios nacionales e internacionales. Fuente: elaboración propia.

\subsection{Interacciones y fidelización}

El éxito de un mensaje se mide por el número de interacciones que la audiencia ha mantenido con el contenido de una publicación, pero también por el publicaciones. Si se observan los gráficos 3 y 4 , se entiende que el crecimiento de la prensa española es mayor que el resto, con un 30,5\% en este último año en relación a su total. Sin embargo, las medias de publicaciones diarias de los medios internacionales son superiores. Escenario que avanza las posibilidades de desarrollo que tiene por delante la prensa española en Instagram.

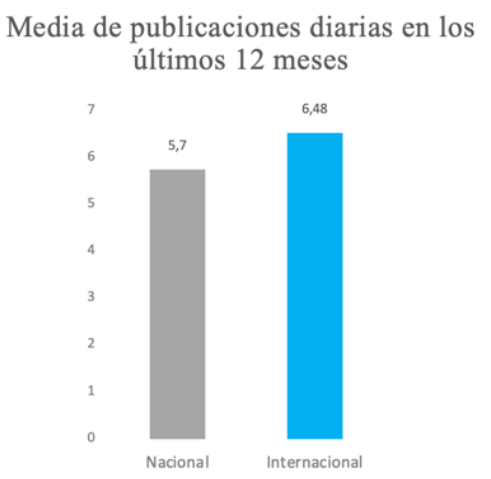

Gráfico 5 Media diaria de las publicaciones realizadas por los medios nacionales e internacionales.

Fuente: elaboración propia.

incremento de nuevos seguidores que ese contenido ha logrado sumar. Dos variables que se analizarán en este segmento distribuidas de la siguiente manera: a) interacciones (likes y comentarios) y b) porcentaje de crecimiento de la audiencia en el periodo de estudio. 


\begin{tabular}{|l|c|c|c|c|}
\hline \multicolumn{1}{|c|}{ Nacional } & Likes 365 & \multicolumn{1}{c|}{ Comments 365 } & \multicolumn{1}{c|}{ Engagemen1 } & 1 Post \\
\hline El País & 11.665 .130 & 316.513 & 11.981 .643 & 6.922 \\
\hline El Mundo & 11.458 .490 & 410.752 & 11.869 .242 & 5.250 \\
\hline ABC & 8.582 .133 & 332.331 & 8.914 .464 & 3.446 \\
\hline La Vanguardia & 14.755 .402 & 369.091 & 15.124 .493 & 5.018 \\
\hline El Español & 926.476 & 88.712 & 1.015 .188 & 710 \\
\hline elDiario.es & 3.391 .050 & 162.689 & 3.553 .739 & 3.612 \\
\hline El HuffPost & 7.991 .048 & 340.605 & 8.331 .653 & 6.489 \\
\hline 20 Minutos & 1.071 .223 & 82.577 & 1.153 .800 & 715 \\
\hline \multicolumn{1}{|c|}{ Internacional } & Likes 365 & Comments 365 & Engagemen1 & 1 Post \\
\hline Le Monde & 5.484 .606 & 83.092 & 5.567 .698 & 4.336 \\
\hline Le Parisien & 1.155 .006 & 33.773 & 1.188 .779 & 3.112 \\
\hline Le Figaro & 2.655 .760 & 88.755 & 2.744 .515 & 2.212 \\
\hline Bild & 15.243 .050 & 391.923 & 15.634 .973 & 8.268 \\
\hline FAZ & 14.715 .444 & 499.934 & 15.215 .378 & 3.599 \\
\hline Corriere della Sera & 59.760 .887 & 982.217 & 60.743 .104 & 8.829 \\
\hline La Repubblica & 45.458 .176 & 720.037 & 46.178 .213 & 19.121 \\
\hline The Guardian & 34.484 .272 & 683.505 & 35.167 .777 & 36.481 \\
\hline The Times & 2.205 .373 & 45.099 & 2.250 .472 & 2.433 \\
\hline The New York Times & 119.986 .231 & 1.790 .579 & 121.776 .810 & 69.310 \\
\hline Washington Post & 73.441 .707 & 2.231 .096 & 75.672 .803 & 35.544 \\
\hline
\end{tabular}

Tabla 3. Interacciones de los medios nacionales e internacionales. Fuente: Elaboración propia.

En la tabla 3 se puede observar el acumulado de likes y comentarios obtenidos por los medios estudiados durante este periodo. Mientras que en la columna de engagement se realiza un sumatorio de todas estas acciones. Asimismo, se ha hallado el número de reacciones (likes y comentarios) que un post alcanza de media por periódico. De esta manera, se advierte que, en la prensa española, el diario El País es el medio que obtiene una mayor cifra de respuestas de los usuarios, seguido de El HuffPost, a cierta distancia del resto. En la esfera internacional las rotativas angloparlantes han logrado unas cifras de interacciones muy significativas. Aspecto que debe valorarse en consideración con la base de seguidores que estos medios arrastran y que es muy poderosa. La casuística de España, en una escala menor, alude a un escenario similar si consideramos su base de seguidores y una potente inversión en esta plataforma en años anteriores. Una formula que rompe El HuffPost, pues con un número reducido de audiencia consigue una penetración alta en Instagram logrando una gran cantidad de likes y comentarios. Este hecho reafirma la importancia de la actividad de los usuarios, pero también el tipo de noticias que eligen publicar en esta red social.

Y por último, se analizará a continuación el porcentaje de incremento de la audiencia. En ambos casos, las cifras de crecimiento que se han agrupado en la tabla 4 son notables. En la prensa española destaca por encima del resto El HuffPost con un $87,85 \%$ de ganancia, que se traduce en 124.695 nuevos seguidores. Hazaña que evidencia una buena estrategia para adquirir nuevos seguidores en Instagram. De igual modo, este hecho mantiene una estrecha similitud con los resultados obtenidos por este diario en número de interacciones, como se ha expuesto anteriormente. Igualmente remarcable ha sido el trabajo de El Mundo con casi un 50\% de nuevos seguidores en doce meses. Ambos periódicos registran grandes resultados, pero se ha de anotar que el resto de las rotativas nacionales no bajan del 30\%. Cifras realmente representativas del momento transcendental que la prensa está experimentando en Instagram.

A pesar de la madurez de las rotativas internacionales en esta plataforma también siguen adquiriendo nuevos usuarios con números muy similares a los españoles. Llama especialmente la atención el diario The Washington Post que siendo uno de los que primero comenzaron en esta red social, su cuota de ganancia está por encima del $40 \%$ en estos doce meses consiguiendo más de 14 millones de nuevos seguidores. Evidentemente no todos los diarios internacionales, como se ha puesto de manifiesto, se comportan como las rotativas angloparlantes que parecen no tener techo en esta red social. Así pues, el resto de diarios sí denotan un trabajo en resultados y estrategias muy parecido al español. 


\begin{tabular}{|c|c|c|c|}
\hline Nacional & Seguidores & S. Ganados & $\%$ Crecimiento \\
\hline El País & 1.201 .632 & 278.769 & $30.21 \%$ \\
\hline El Mundo & 553.815 & 177.639 & $47.22 \%$ \\
\hline $\mathrm{ABC}$ & 381.999 & 96.824 & $33.95 \%$ \\
\hline La Vanguardia & 558.788 & 134.933 & $31.83 \%$ \\
\hline El Español & 95.445 & 26.594 & $38.63 \%$ \\
\hline elDiario.es & 162.209 & 39.994 & $32.72 \%$ \\
\hline El HuffPost & 266.630 & 124.695 & $87.85 \%$ \\
\hline 20 Minutos & 204.584 & 51.718 & $33.83 \%$ \\
\hline Internacional & Seguidores & S. Ganados & $\%$ Crecimiento \\
\hline Le Monde & 1.482 .626 & 307.679 & \begin{tabular}{|l|}
$26.19 \%$ \\
\end{tabular} \\
\hline Le Parisien & 41.528 & 101.511 & $32.35 \%$ \\
\hline Le Figaro & 523.061 & 104.186 & $24.87 \%$ \\
\hline Bild & 643.781 & 121.620 & $23.29 \%$ \\
\hline FAZ & 473.834 & 133.181 & $39.1 \%$ \\
\hline Corriere della Sera & 1.084 .165 & 357.322 & $49.16 \%$ \\
\hline La Repubblica & 1.493 .284 & 390.582 & $35.42 \%$ \\
\hline The Guardian & 4.462 .845 & 1.061 .715 & $31.22 \%$ \\
\hline The Times & 815.789 & 170.247 & $26.37 \%$ \\
\hline The New York Times & 13.270 .907 & 3.704 .266 & $38.72 \%$ \\
\hline Washington Post & 4.821 .556 & 1.458 .782 & $43.38 \%$ \\
\hline
\end{tabular}

Tabla 4. Porcentaje del número de seguidores obtenidos por las diferentes cuentas. Fuente: elaboración propia.

No obstante, la media de crecimiento de la audiencia en España ha sido mayor que sus homólogos internacionales en estos doce meses como se recoge en gráfico 6.

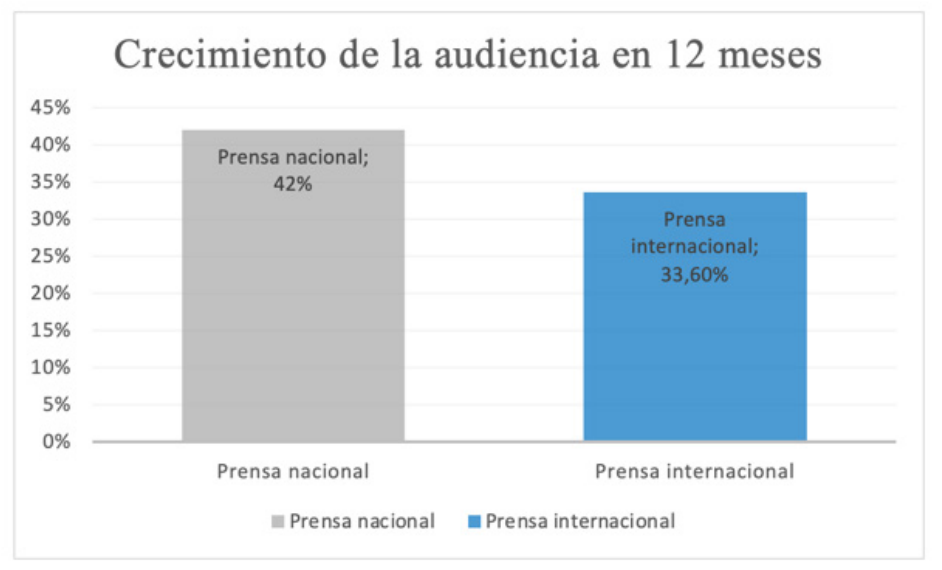

Gráfico 6 Comparativa nacional e internacional del número de seguidores obtenidos por las cuentas analizadas. Fuente: elaboración propia.

\subsection{Composición del mensaje}

Otra de las variables a tener en cuenta en esta plataforma eminentemente visual es la forma en que se transmite la información publicada. Los mensajes se componen de símbolos, palabras y contenido audiovisual. De esta manera, se ha podido cuantificar en este estudio lo siguiente: 1) categoría texto: hashtags y palabras y 2) contenido audiovisual: imágenes y videos. No se ha contemplado el empleo de elementos sonoros como música en tanto que no es determinante en la composición de los mensajes periodísticos en la red.
En la categoría de texto, en la tabla 5 se puede observar cómo los diarios nacionales muestran medias de 561 a 1.120 caracteres por publicación, siendo ésta la elección que más se repite. Poniendo un ejemplo en palabras se pudiera traducir en frecuencias de 120 y 180 por publicación. Sin embargo, se debe también anotar que la composición del mensaje está bastante repartida entre otras alternativas de textos cortos y largos. De igual manera, los hashtags dan cuenta de una situación parecida. La opción más reiterada rivaliza entre el empleo de 3 a 5 hashtags por mensaje con la de ninguna etiqueta, pero de igual modo siguen compartiéndose con otras posibilidades 
como de 6 a 9. Tanto El País como 20 Minutos tienden a no incluir hashtags en los textos. Una estrategia que veremos que se repite con frecuencia en la prensa internacional.

\begin{tabular}{|c|c|c|c|c|}
\hline Instagram & \# Hashtags & $\%$ & N. Caracteres & $\%$ \\
\hline El País & 0 & $67,15 \%$ & $561-1120$ & $45,54 \%$ \\
\hline El Mundo & $3-5$ & $95,64 \%$ & 561-1120 & $44,14 \%$ \\
\hline $\mathrm{ABC}$ & 0 & $82,16 \%$ & $561-1120$ & $45,78 \%$ \\
\hline La Vanguardia & $3-5$ & $64,30 \%$ & $1121+$ & $43,62 \%$ \\
\hline El Español & $6-9$ & $55,06 \%$ & $1121+$ & $31,04 \%$ \\
\hline elDiario.es & $3-5$ & $46,47 \%$ & 561-1120 & $46,47 \%$ \\
\hline El HuffPost & $6-9$ & $61,94 \%$ & $561-1120$ & $54,86 \%$ \\
\hline 20 Minutos & 0 & $46,87 \%$ & $281-560$ & $29,69 \%$ \\
\hline
\end{tabular}

Tabla 5. Porcentaje de \# Hashtags y caracteres empleados por las cuentas nacionales seleccionadas. Fuente: elaboración propia.

En los medios internacionales se puede observar en la tabla 6 una situación muy similar en el uso de hashtags. Las opciones que más se repiten son 3 a 5 o ninguno, aunque las medias de estos últimos son realmente elevadas, escenario que confirmaría un uso de los hashtags minoritario. Asimismo, en el número de caracteres encontramos idéntica diversificación que en la prensa española. La variante más usada es de 561 a 1.120 caracteres, pero está igualmente repartida entre textos más breves y prolijos.

\begin{tabular}{|c|c|c|c|c|}
\hline Instagram & \# Hashtags & $\%$ & N. Caracteres & $\%$ \\
\hline Le Monde & $3-5$ & $81,8 \%$ & $1121+$ & $87,5 \%$ \\
\hline Le Parisien & $3-5$ & $58,5 \%$ & $281-560$ & $54,9 \%$ \\
\hline Le Figaro & $3-5$ & $48,0 \%$ & $281-560$ & $48,1 \%$ \\
\hline BILD & $3-5$ & $37,4 \%$ & $561-1120$ & $47,9 \%$ \\
\hline FAZ & $6-9$ & $35,3 \%$ & $281-560$ & $71,6 \%$ \\
\hline Corriere della Sera & 0 & $86,6 \%$ & $561-1120$ & $36,2 \%$ \\
\hline La Repubblica & $3-5$ & $42,8 \%$ & $1121+$ & $43,9 \%$ \\
\hline The Guardian & 0 & $81,1 \%$ & $561-1120$ & $48,7 \%$ \\
\hline The Times & 0 & $85,3 \%$ & $561-1120$ & $45,2 \%$ \\
\hline The New York Times & 0 & $97,0 \%$ & $1121+$ & $77,4 \%$ \\
\hline Washington Post & 0 & $98,2 \%$ & $561-1120$ & $60,2 \%$ \\
\hline
\end{tabular}

Tabla 6 Porcentaje de \# Hashtags y caracteres empleados por las cuentas internacionales seleccionadas. Fuente: elaboración propia.

Como se ha advertido, una de las grandes ventajas de esta red social reside en el manejo y distribución de imágenes. Un contenido que poco a poco empieza a competir con el formato video. Instagram posibilita diseñar las publicaciones agregando: 1) una imagen por sí misma; 2) varias imágenes denominado carousel; y 3) la inclusión de un video. En este sentido, han proliferado un sinfín de aplicaciones que trabajan las composiciones de fotografías e interactúan con la propia aplicación de forma más que significativa, como es el caso de aplicaciones como Layout, PicsArt Photo Editor o StroyLuxe, entre otras.

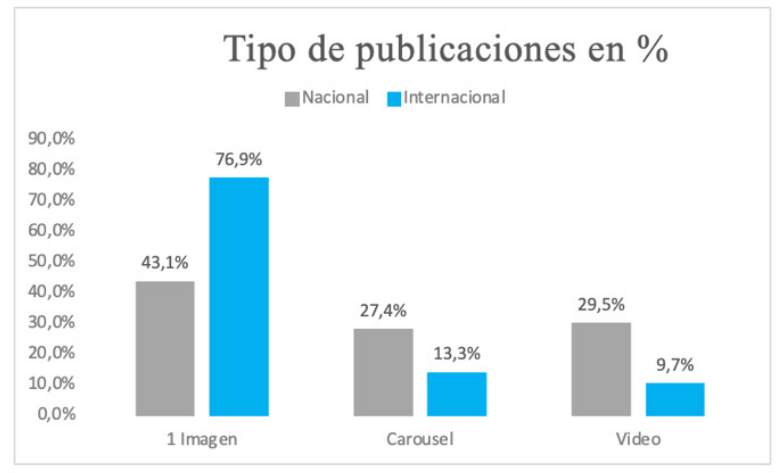

Gráfico 7 Porcentaje del tipo de publicaciones utilizadas por los medios nacionales e internacionales analizados. Fuente: Elaboración propia. 
En el análisis efectuado que se presenta en el gráfico 7 se han contabilizado las publicaciones en función de estas variables. La posición de la prensa internacional es rotunda sobre la elección de una sola imagen en el diseño del mensaje, mientras que en los diarios nacionales las opciones están algo más abiertas y repartidas. Llama poderosamente la atención el porcentaje de videos en las publicaciones de los diarios españoles, pues es tres veces superior que sus homólogos en el extranjero. Una tendencia que también está en aumento en otras redes socia-

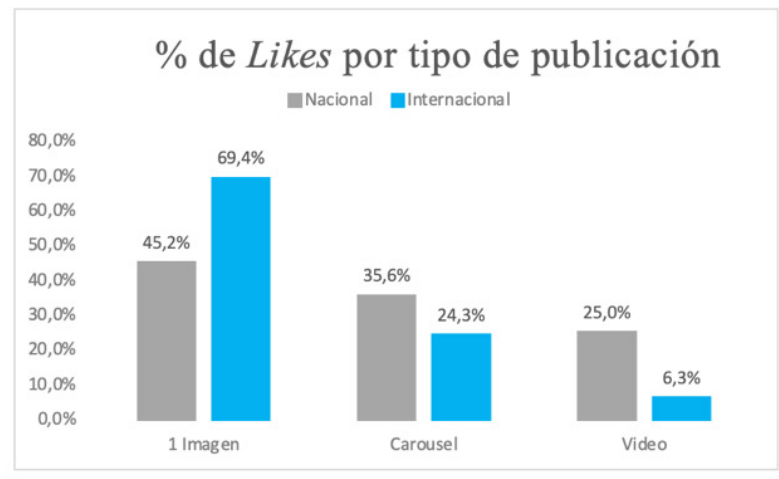

Gráfico 8 Porcentaje de likes por tipo de publicación. Fuente: Elaboración propia.

En este momento, se hace preciso aclarar que el formato carousel puede estar constituido por imágenes fijas y vídeos cortos con una duración de 30 segundos. Aspecto que ha sido imposible analizar de forma independiente. Del mismo modo, en los gráficos 8 y 9 se puede observar una correspondencia de cifras entre el número de publicaciones y las interacciones obtenidas, aunque existen también algunos matices que deben ser anotados. En la prensa española las imágenes generan más likes que el carousel y el video. Sin embargo, el formato audiovisual impulsa el número de comentarios por encima del ratio de publicación. De la misma manera, en las cabeceras internacionales suben las interacciones con el carousel y se desploman con el video que evidencia por tanto que no es un formato demandado por el público internacional que sigue a estos medios.

\section{Conclusiones}

Instagram es una de las redes sociales que mayor crecimiento ha experimentado en los últimos años y, para la prensa, esta circunstancia no ha pasado desapercibida. No hace mucho hubiera sido complejo pensar que las publicaciones audiovisuales de noticias en redes sociales pudieran convertirse en una futura vía de negocio para este sector, pero estrategias como la llevada a cabo por otras plataformas como YouTube han ido allananado este camino. La prensa poco a poco ha empezado a incrementar su contenido audiovisual y a deslocalizarlo fuera de sus portales con el fin de monetizar ese trabajo y conseguir nue- les como YouTube y Twitter (Díaz-Lucena, et al., 2022). Así pues, la prensa nacional parece adecuarse a las tres modalidades de mensaje que Instagram habilita dependiendo posiblemente del material con el que cuenten. Llegados a este punto, la respuesta del usuario con respecto al contenido se antoja trascendental. De modo que el empleo de imágenes fijas o vídeos pudieran ser determinantes en su reacción final. Se ha querido intentar responder a estas cuestiones midiendo el número de likes y comentarios según el formato del mensaje.

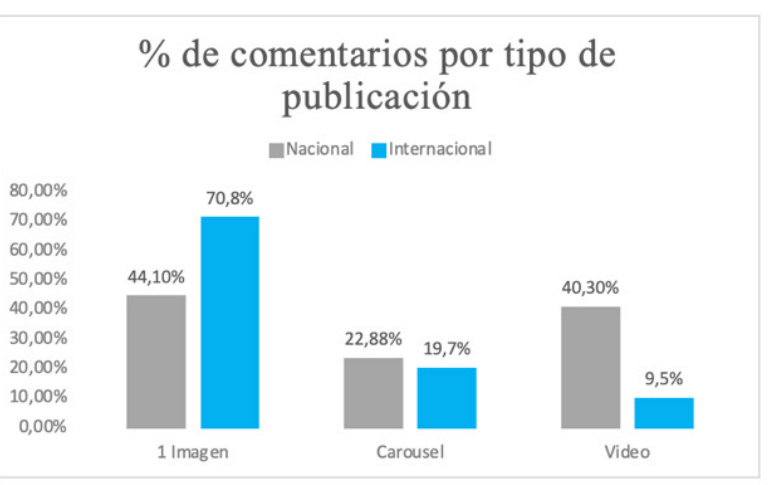

Gráfico 9 Porcentaje de comentarios por tipo de publicación. Fuente: Elaboración propia.

vas interacciones y seguidores. Las publicaciones se han ido especializando y acomodando a las diferentes plataformas de destino para optimizar el eco y la penetración de la información. Así pues, la prensa ha tenido que adecuarlas para transformarlas en piezas más autónomas, es decir, con mayor poder visual donde el texto adjunto ha pasado en muchas de ellas a ser prescindible. De esta manera, los contenidos más independientes, - como son el video de noticias o aquellas imágenes con capacidad para generar una gran cantidad de significación - se han convertido en piezas idóneas para las RRSS donde se prima lo visual y sonoro.

Este estudio nos ha permitido conocer el trabajo que la prensa española ha llevado a cabo durante doce meses en Instagram y se ha advertido el incremento de publicaciones frente a años anteriores. Circunstancia que confirma el objetivo de tener una presencia más activa en esta plataforma aunque los esfuerzos realizados por unos y otros indudablemente no han sido los mismos. A tal efecto, se han detectado grandes diferencias dentro de las rotativas seleccionadas, especialmente entre el bloque de diarios tradicionales (El País, El Mundo, La Vaguardia y ABC) y los nativos digitales (El Español, elDiario.es, 20 Minutos y El HuffPost). Los primeros, que empezaron antes, han adquirido experiencia y alcanzado un número importante de seguidores que en ocasiones les facilita la penetración de sus contenidos en la plataforma. Aunque como se ha demostrado, esta variable no es determinante para lograr eficacia. El primer bloque de cabeceras publica más contenido con medias de 5 a 6 mensajes diarios a diferencia de las 3 a 4 pu- 
blicaciones de las rotativas digitales. Sin embargo, algunos de estos últimos con una inversión menor están obteniendo mejores resultados si se toma como referencia la cifra de interacciones y la adquisición de nuevos seguidores. Sirva como ejemplo el caso de El Huffpost, el cual ha logrado medias de más de seis mil interaciones por mensaje enviado, -un registro similar a El País- pero también un crecimiento de seguidores del $87 \%$ que marca una gran diferencia con el resto. De igual modo, El Mundo se consolida como el diario que más ha destacado y el segundo que mejores resultados ha obtenido de todos los estudiados si tenemos en cuenta registros como son el número de mensajes enviados, el eco y penetración de sus publicaciones (con casi seis mil por cada mensaje), pero también el porcentaje de crecimiento de nuevos seguidores con casi un $45 \%$. Ambos ejemplos ponen de manifiesto una estrategia especialmente efectiva si se miran los resultados obtenidos en esta red social. De igual modo, el crecimiento general de la prensa española en Istagram ha sido remarcable en los doces meses de este estudio, además de estar por encima del ratio alcanzado por las rotativas internacionales escogidas. Una circunstancia que apunta a una llegada más temprana a esta plataforma y que por tanto evidencia un menor techo de desarrollo aunque un mayor conocimiento de la misma. Así pues, este escenario muestra la posibilidad de un mayor margen de progreso y mejora en las rotativas nacionales, como se ha visto en este análisis.

Y por último, se ha detectado un dato que está alcanzando una gran progresión en los medios nacionales y que por tanto se debería hacer seguimiento para observar su desarrollo a corto plazo. Se trata del incremento del número de videos que las rotativas están publicando en Instagram, así como las interaciones que este formato está provocando en la audiencia. Nos encontramos en este momento, especialmente en España, como se ha demostrado en otros trabajos sobre RRSS (Díaz-Lucena et al., 2022), un aumento de la producción de contenidos audiovisuales (videos de noticias o directo en streaming) de los diarios analizados. Una tendencia que también ha llegado a Instagram, como emana de este análisis y que parece marginal en la prensa internacional. Posiblemente, se pueda pronosticar que las publicaciones de contenidos audiovisuales van a seguir creciendo en los próximos años en España, en tanto que los departamentos multimedia de las empresas informativas se están estrutuctutrando, ampliando y apostando por la calidad de sus contenidos para monetizarlos pero también para distinguirse del resto.

\section{Referencias bibliográficas}

AIMC (2021). Marco general de los medios en España. https://www.aimc.es/a1mc-c0nt3nt/uploads/2021/02/marco2021. pdf

Álvarez, J. (2021). El informe sobre las tendencias digitales, redes sociales y mobile. We Are Social, 27 enero. https://wearesocial.com/es/blog/2021/01/digital-report-2021-el-informe-sobre-las-tendencias-digitales-redes-sociales-y-mobile

Benaissa Pedriza, S. (2018). Las redes sociales como fuente de información periodística en la prensa digital española (El País, El Mundo, La Vanguardia y ABC). Index.comunicación, 8(3), 13-42. E-ISSN: 2174-1859.

Burum, I. y Quinn, S., (2015) MOJO: the mobile journalism handbook: how to make broadcast videos with an iPhone or iPad. Taylor \& Francis, London. https://doi.org/10.4324/9781315740294

Canavilhas, J., Satuf, I. y Baccin, A. (2016). El futuro del periodismo está en el ecosistema móvil. En H. Sánchez. (Ed.), Nuevos retos para el periodista. Innovación, creación y emprendimiento, 149-173. Valencia: Tirant Humanidades. ISBN 9788416556151.

Díaz-Lucena, A., Mora de la Torre, V., Torres Hortelano, L. J. (2022). Strategies of the Spanish press due to the change of the Twitter algorithm. Analysis of the tweets published between 2018-2020. Communication \& Society, 35(1), 197213. https://doi.org/10.15581/003.35.1.197-213.

Ditrendia (2020) Informe Mobile en España y en Mundo 2020. Ditrendia. https://ditrendia.es/informe-mobile-2020/

García-Avilés, J. A., (2015). El desarrollo del video informativo en la red: formatos y casos de éxito. En

L. Núñez-Ladeveze, Periodismo en la Red. Géneros, estilos y normas, 251-284. Madrid: Universitas.

ISBN:9788479914417.

Góngora Díaz, G. y Lavilla Muños, D.J. (2020). La importancia de la construcción de marca en Instagram para las empresas periodísticas. En Estudios multidisciplinarios en comunicación audiovisual, interactividad y marca en la red, pp. 129-138. ISBN 9788418167171.

Hedley, D., (2012) Social moments in solo videojournalism. Digital Journalism, September 13th http://dx.doi.org/10.10 $80 / 21670811.2012 .716630$

Herrera Damas, S. y Requejo Alemán, J.L. (2012). 10 Good Practices for News Organizations Using Twitter. Journal of Applied Journalism \& Media Studies, 1, (1), 79-95. https://doi.org/10.1386/ajms.1.1.79 1

Herrero Curiel, E. (2012). El periodismo en el siglo de las redes sociales. Vivat Academia, (117E), 1113-1128. https://doi. org/10.15178/va.2011.117E.1113-1128

IAB (2021). Estudio Anual de redes sociales. https://iabspain.es/estudio/estudio-de-redes-sociales-2021/ 
Kalogeropoulos, A. y Nielsen, R. (2017). Investing in online video news: A cross-national analysis of news organizations' enterprising approach to digital media. Journalism Studies, 19 (15) pp. 2207-2224. https://doi.org/10.1080/1461670X.2017.1331709

Longhi-Heredia, Sebastian \& Quezada Tello, Laddy. (2021). La prensa en Instagram: El uso de la fotografía asociada al patrimonio cultural en España. En Cosmovisión de la comunicación en redes sociales en la era postdigital McGraw-Hill, pp.127-150. ISBN 978-84-486-2583-2.

Mayoral Sánchez, J., Abejón Mendoza,P. y Morata Santos, M. (2016): El vídeo en la prensa digital española: 2010-2015. Revista Latina de Comunicación Social, 71,775-799. https://doi.org/10.4185/RLCS-2016-1120

Pérez-Soler, S. (2017). Periodismo y redes sociales: Claves para la gestión de contenidos digitales. Barcelona, UOC. ISBN: 9788491169864

Santín, M., \& Álvarez-Monzoncillo, J. M. (2020). The use of YouTube by the Spanish press: A model

to be defined. Profesional De La Información, 29 (1) 1-14 https://doi.org/10.3145/epi.2020.ene.16

Shearer, Elisa, Mitchell, Amy (2021). News use across social media platforms in 2020.

Pew Research, 12 ${ }^{\text {th }}$ Jan. https://www.pewresearch.org/journalism/wp-content/uploads/sites/8/2021/01/PJ_2021.01.12_ News-and-Social-Media_FINAL.pdf 